\title{
Performance Evaluation of Interior Permanent Magnet Motors Using Thin Electrical Steels
}

\author{
Thanh Anh Huynh* Non-member, Min-Fu Hsieh ${ }^{* a)}$ Non-member
}

(Manuscript received Jan. 21, 2017, revised July 11, 2017)

\begin{abstract}
This work investigates the impact of thin electrical steel laminations on the performance of interior permanent magnet (IPM) motors for electric vehicle tractions. Three different electrical steel grades are used in IPM motor designs and the performance is evaluated by simulation. It is found that thin laminations can improve the efficiency of the IPM motor, but the output torque could be slightly reduced due to low saturation flux density. Therefore, direct replacement of core materials for the same motor design may not be suitable. This paper presents the considerations for the design of IPM motors using thin laminations. The motor performance, including torque, efficiency, and constant power speed range is evaluated. A process is developed for the design of high performance IPM motors using thin laminations. Experimental studies are conducted to validate the simulations and designs.
\end{abstract}

Keywords: traction motor, IPM motor, thin lamination, field-weakening control

\section{Introduction}

Interior permanent magnet (IPM) motors are considered to be an excellent candidate for tractions of electric vehicle (EV) due to their high efficiency, high torque/power density and wide constant power speed range ${ }^{(1)}$. The requirements of lightweight and compactness for EV powertrains lead to high speed design of traction motors and this would require the iron loss to be minimized to maintain the efficiency. Therefore, thin electric steel laminations are gaining more and more popularity for high speed traction motors. However, thin laminations (e.g., $0.2 \mathrm{~mm}$ or thinner) usually possess lower saturation flux density than common ones (e.g., 0.5 or $0.35 \mathrm{~mm}$ ). This may bring the output torque slightly lower and this is disadvantageous for high torque operation of EVs at low speed. Therefore, the effect of such materials used for traction motors should be carefully evaluated.

Many studies have analyzed the applications of different electrical steels to electric motors but mainly focused on core loss and efficiency ${ }^{(2)-(7)}$. The torque characteristics and efficiency of IPM motors using high-strength non-oriented electrical steel were enhanced compared to those using other materials ${ }^{(8)}$. Grain oriented electrical steel was used to replace conventional non-oriented electrical steel for axial flux switched reluctance motors in (9) and the result revealed an over $20 \%$ torque improvement. Four electrical steel grades were employed in (10) for synchronous reluctance motors and their $d-q$ axis inductance were investigated.

From above discussions, two major research trends regarding electrical steels for electric motors can be observed: (a) high flux density materials to increase the torque or

a) Correspondence to: Min-Fu Hsieh. E-mail: mfhsieh@mail. ncku.edu.tw

* Department of Systems and Naval Mechatronic Engineering, National Cheng Kung University

1, University Road, Tainan, Taiwan performance, and (b) high-strength and low-iron-loss materials to increase the efficiency at high speed or rotor strength. However, few studies have reported design and analysis to achieve both high torque and high efficiency using thin laminations. Note that thin laminations are still costly. Hence, using different materials for stator and rotor may satisfy the targets of high torque, high efficiency at high speed and low material cost.

This paper first presents the performance evaluation of IPM motors using thin laminations. The benefits of combining different materials, i.e., high saturation flux density and low iron loss to improve the motor performance and reduce the material cost are also investigated. This would be an alternative solution to designs with low material cost and high performance if motor production with stator and rotor having different materials can be easily fulfilled. Three materials are employed in this study: one thin lamination and two high saturation flux density materials. A $10 \mathrm{~kW}$ IPM motor is designed as the case study. The motor performance is evaluated based on torque output, efficiency, and flux-weakening ability for constant power speed range (CPSR), which is an important performance index for EV application. Finite element method (FEM) is used for analysis. A prototype is fabricated and the designs and simulations are validated by experiments. Note that the mechanical strength of thin laminations for high speed applications is not discussed in this paper.

\section{Analysis of IPM Motor}

The main specifications and parameters of the target $10 \mathrm{~kW}$ IPM traction motor are given in Table 1. Five different motor designs based on two configurations are studied, as shown in Fig. 1, where the permanent magnet (PM) are arranged to be double-layer and triangular. These configurations are commonly employed in electric vehicles with a decent flux weakening capability and therefore their performances using different electrical steels (including thin laminations) may be 
Table 1. Specifications of $10 \mathrm{~kW}$ IPM motor

\begin{tabular}{ll}
\hline Parameters/Specifications & Value (Unit) \\
\hline Maximum torque & $54 \mathrm{Nm}$ \\
\hline Maximum speed & $9000 \mathrm{RPM}$ \\
\hline Maximum current & $110 \mathrm{~A}$ \\
\hline Maximum voltage & $220 \mathrm{Vrms}$ \\
\hline Number of phase & 3 \\
\hline Number of poles & 8 \\
\hline Number of slot & 36 \\
\hline Stator diameter & $160 \mathrm{~mm}$ \\
\hline Stack length & $86 \mathrm{~mm}$ \\
\hline Air-gap length & $0.5 \mathrm{~mm}$ \\
\hline
\end{tabular}

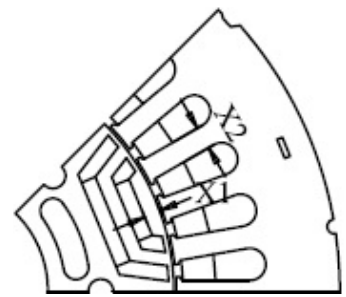

(a) Double PM layers.

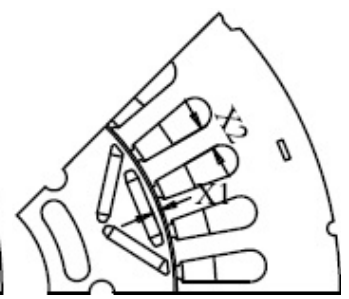

(b) Triangular PM arrangements.
Fig. 1. Two rotor configurations of $10 \mathrm{~kW}$ IPM motor

Table 2. Design parameters of five IPM motor designs

\begin{tabular}{cccccc}
\hline & \multicolumn{3}{c}{ Double PM layers } & \multicolumn{2}{c}{ Triangular PM } \\
\hline Items & Motor 1 & Motor 2 & Motor 3 & Motor 4 & Motor 5 \\
\hline $\mathbf{X 1} \mathbf{( m m )}$ & 3.3 & 2.3 & 3.3 & 1.5 & 1.5 \\
\hline $\mathbf{X 2}(\mathbf{m m})$ & 4.47 & 4.47 & 4 & 4.47 & 5.5 \\
\hline Number of slots & 36 & & 36 & 33 \\
\hline Rotor size (mm) & \multicolumn{5}{c}{160} \\
\hline Stator size $(\mathbf{m m})$ & \multicolumn{5}{c}{7740} \\
\hline PM volume $\left(\mathbf{m m}^{\mathbf{3}}\right)$ & $\mathrm{N} 35 \mathrm{H}\left(\mathrm{NdFeB}, B_{r}=1.19 \mathrm{~T}, H_{c}=915 \mathrm{kA} / \mathrm{m}\right.$ at $\left.20^{\circ} \mathrm{C}\right)$ \\
\hline PM Material
\end{tabular}

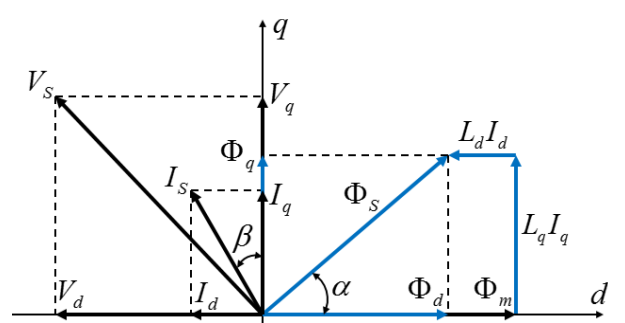

Fig. 2. The stator flux linkage in the $d-q$ reference frame

worth studying. The design parameters of the five IPM motors are given in Table 2.

2.1 Mathematical Model of IPM Motor The phasor diagram in the d-q reference frame as shown in Fig. 2 is used to analyze the IPM motor characteristics.

The $d$ - and $q$-axis currents $I_{d}$ and $I_{q}$ can be given as

$$
I_{d}=-I_{s} \sin \beta, \quad I_{q}=I_{s} \cos \beta
$$

where $\beta$ is current angle and $I_{s}=\sqrt{I_{d}^{2}+I_{q}^{2}}$.

The $d$ - and $q$-axis voltages can be expressed as

$$
\begin{aligned}
& V_{d}=R_{s} I_{d}-\omega \Phi_{q}=R_{s} I_{d}-\omega L_{q} I_{q} \cdots \cdots \cdots \cdots \cdots \\
& V_{q}=R_{s} I_{q}+\omega \Phi_{d}=R_{s} I_{q}+\omega L_{d} I_{d}+\omega \Phi_{m} \cdots \cdots \cdots
\end{aligned}
$$

where $\Phi_{d}$ and $\Phi_{q}$ are the $d$ - $q$-axis flux linkages respectively; $L_{d}$ and $L_{q}$ are the $d$ - $q$-axis inductances, respectively; $\Phi_{m}$ is the PM flux linkage; $R_{s}$ is the phase resistance; $\omega$ is the electrical angular speed, and

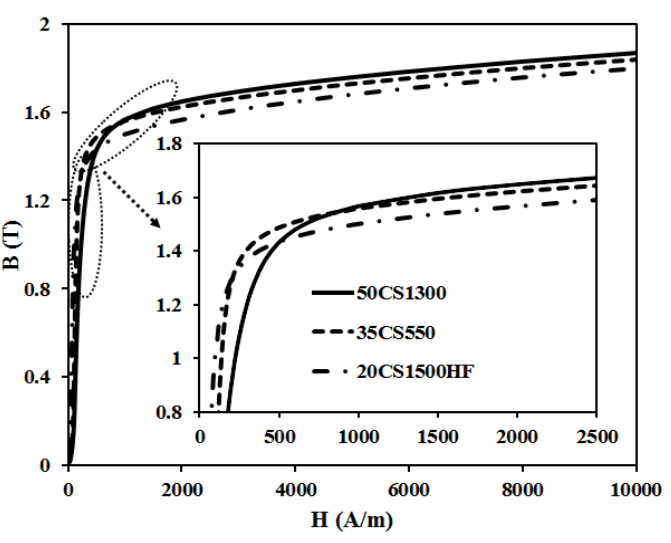

(a)

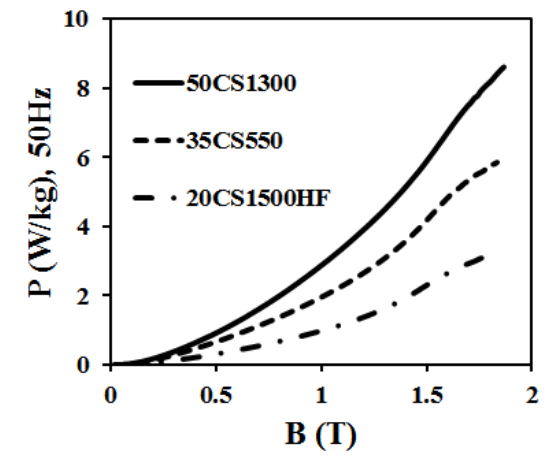

(b)

Fig. 3. Electric steel characteristics: (a) B-H curves; (b) core loss data

$$
\begin{aligned}
\Phi_{d} & =L_{d} I_{d}+\Phi_{m}, \quad \Phi_{q}=L_{q} I_{q} \ldots \ldots \ldots \ldots \ldots \ldots \ldots \ldots \ldots \ldots \ldots \ldots \ldots \ldots \ldots \ldots \ldots \ldots
\end{aligned}
$$

Note that the excitation current $I_{s}$ should not exceed the maximum allowable current (the current limit to produce the peak torque). The electromagnetic torque $\left(T_{e}\right)$ of IPM motors consists of two components: the mutual torque and reluctance torque and can be calculated by

$$
T_{e}=\frac{3}{2} \frac{P}{2}\left[\Phi_{m} I_{q}-\left(L_{d}-L_{q}\right) I_{d} I_{q}\right]
$$

where $P$ is the number of poles.

Note that the torque in (6) does not consider the influence of iron losses and mechanical loss. To evaluate the effect of electrical steels on the motor performance, iron losses are computed here using FEM based on the iron loss models of the materials employed without considering the effect of pulse-width modulation (PWM) switching.

2.2 Characteristics of Electrical Steels The B-H curves of the three electrical steels (produced by China Steel Corp., Taiwan) are given in Fig. 3(a). As can be seen, 50CS1300 possesses the highest saturation flux density in comparison with the other two. One drawback of thin electrical steel material $(20 \mathrm{CS} 1500 \mathrm{HF})$ is the low saturation flux density despite its low iron loss [Fig. 3(b)]. This makes it suitable for high speed operation (if mechanical strength is not considered) but disadvantageous for high torque output.

2.3 Material Combinations for IPM Motors The core loss of IPM motors is calculated using FEM with the data shown in Fig. 3(b). From the three materials, seven material combinations for the stator and rotor are considered, as 
Table 3. Material combinations (based on Motor 1)

\begin{tabular}{ccc}
\hline Model No. & Materials & Denoted \\
\hline Case 1 & $50 \mathrm{CS} 1300(\mathrm{R}+\mathrm{S})$ & $\mathrm{T} 1$ \\
\hline Case 2 & $35 \mathrm{CS} 550(\mathrm{R}+\mathrm{S})$ & $\mathrm{T} 2$ \\
\hline Case 3 & $20 \mathrm{CS} 1500 \mathrm{HF}(\mathrm{R}+\mathrm{S})$ & $\mathrm{T} 3$ \\
\hline Case 4 & $20 \mathrm{CS} 1500 \mathrm{HF}(\mathrm{R})+35 \mathrm{CS} 550(\mathrm{~S})$ & $\mathrm{T} 4$ \\
\hline Case 5 & $20 \mathrm{CS} 1500 \mathrm{HF}(\mathrm{R})+50 \mathrm{CS} 1300(\mathrm{~S})$ & $\mathrm{T} 5$ \\
\hline Case 6 & $35 \mathrm{CS} 550(\mathrm{R})+20 \mathrm{CS} 1500 \mathrm{HF}(\mathrm{S})$ & $\mathrm{T} 6$ \\
\hline Case 7 & $50 \mathrm{CS} 1300(\mathrm{R})+20 \mathrm{CS} 1500 \mathrm{HF}(\mathrm{S})$ & $\mathrm{T} 7$ \\
\hline
\end{tabular}

Note: $\mathrm{R}$ is rotor and $\mathrm{S}$ is stator.

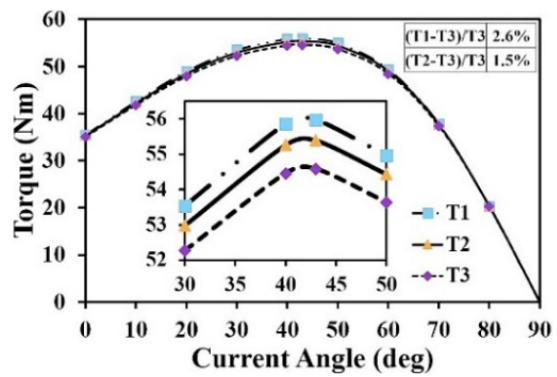

Fig. 4. Torque comparison of three electrical steel materials (@110 A current)

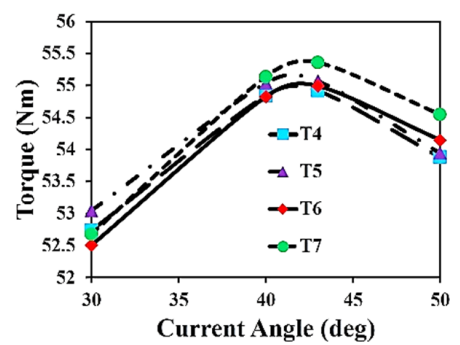

Fig. 5. Torque characteristics of the combining electrical steel materials (@110 A current)

listed in Table 3. For a fair and direct comparison, the geometry, meshes, nodes and elements are constructed in the same condition for all the cases, which are all based on the same motor, i.e., "Motor 1", as shown in Fig. 1(a) and Table 2.

2.4 Results and Discussion-Torque Output To evaluate the effect of the combined materials, the operating condition at the peak torque (and the peak current $110 \mathrm{~A}$ ) and a speed of $1800 \mathrm{rpm}$ is first considered, where the output power is maximum and saturation could occur. Therefore, Fig. 4 shows the torque characteristics of cases T1, T2, and $\mathrm{T} 3$ at the peak current with varying current angles $(\beta)$. Each of these three cases employs the same material for its stator and rotor but the materials are different for one case from another. As can be seen, the torque of models T1 (50CS1300) and T2 (35CS550) is respectively $2.6 \%$ and $1.5 \%$ higher than that of T3 (20CS1500HF). This is mainly due to different material saturation flux densities.

In the cases of using different materials for the stator and rotor, the simulation in Fig. 5 shows that the condition is similar to the previously discussed cases, around $2 \%$ difference between the highest and lowest cases. Model T7, with a 20CS1500 stator and 50CS1300 rotor, produces the highest torque. The torque is higher than that of T2 and T3 and very close to $\mathrm{T} 1$. Note that the excitation currents are the same for all the models.
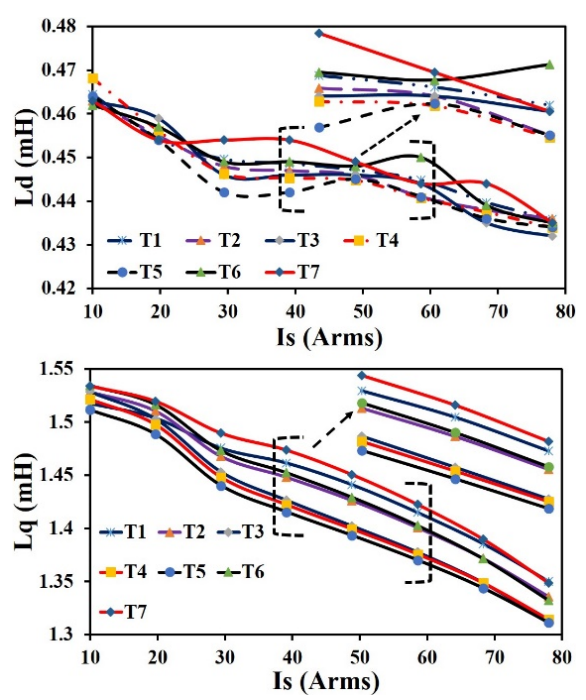

Fig. 6. $d-q$ axis inductances of IPM motor with different currents at $43^{\circ} \mathrm{E}$ current angle

\section{Discussion:}

The above results invoke some discussions regarding the material effect, as listed in the following.

(a) The stator is subject to alternating flux and using thin lamination is advantageous for high efficiency design.

(b) The rotor is used to produce field and the majority of flux does not alternate (disregarding armature reaction and PWM switching). Thus, the rotor seems to be less sensitive to iron loss.

(c) The use of materials with high saturation flux density for the rotor can indeed improve torque output but the stator with a lower saturation flux density may bring the flux level and torque down slightly.

(d) Employing thin laminations for both stator and rotor to improve efficiency at high speed, the slightly reduced torque may be recovered by proper design.

(e) As shown in Figs. 4 and 5, for all the models, the peak torque occurs at a current angle of around $43^{\circ} \mathrm{E}$ under maximum voltage operation.

Figure 6 shows the variation of $d$ - $q$-axis inductances with different currents at a fixed current angle of $43^{\circ} \mathrm{E}$, where the motor torque reaches its maximum at the peak current. The different inductances between these models may be partly caused by their permeabilities. Note that the differences of the inductances in all the modes are small. This may explain why the motor performance with combined materials is almost the same as that with identical material. Therefore, the motor torque [defined by Eq. (6)] can hardly be improved by manipulating the inductance using different electrical steels materials.

2.5 Results and Discussion-Iron Loss and Efficiency

The simulations shown in Fig. 7 are conducted based on the iron loss models given by the material provider for various speeds and frequencies. The influence of PWM harmonics is not considered in the analysis. Therefore, in practice, the iron loss in the rotor may be greater than predicted due to the PWM harmonics effect. It can be seen from Fig. 7 that the iron loss in the stator is larger than that in the rotor. This is expected due to the alternating flux in the stator. 


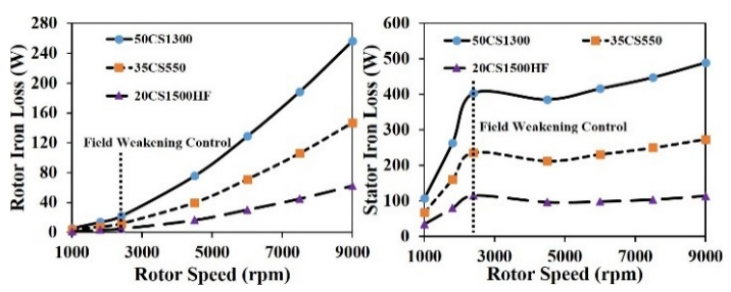

Fig. 7. The iron loss of IPM motor in rotor and stator

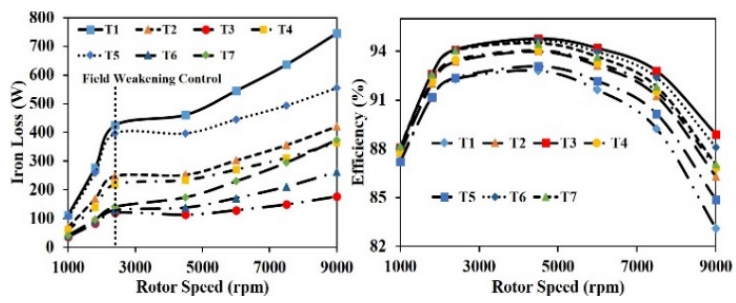

Fig. 8. The efficiency with different electric steel materials

Also expectedly, the rotors or stators using thin lamination have much less iron loss than that of the thick one. The stator iron loss drops after $2400 \mathrm{RPM}$ are due to the introduction of flux weakening. In Fig. 8, T1 has the highest iron loss while $\mathrm{T} 3$ has the lowest (the efficiency of $\mathrm{T} 3$ is $2.5 \%$ higher than T1). Both T6 [35CS550(R) + 20CS1500HF(S)] and $\mathrm{T} 7[50 \mathrm{CS} 1300(\mathrm{R})+20 \mathrm{CS} 1500 \mathrm{HF}(\mathrm{S})]$ have lower iron loss than T4 [20CS1500HF(R) + 35CS550(S)] and T5 $[20 \mathrm{CS} 1500 \mathrm{HF}(\mathrm{R})+50 \mathrm{CS} 1300(\mathrm{~S})]$. The efficiency of T6 and $\mathrm{T} 7$ is slightly higher than that of T4 and T5. The results shown in Figs. 7 and 8 are calculated at the peak current of $110 \mathrm{~A}$, whose current angles vary from low speed up to the maximum speed $(9000 \mathrm{rpm})$. It can also be observed that the iron loss in the stator using different materials has the larger difference than that in the rotor and therefore low-iron-loss materials should be used for the stator.

Discussion

From the above results, it can be observed that:

(a) Although material combinations can hardly enhance motor torque but improve iron loss and efficiency. It also leads to reducing the material cost.

(b) The iron loss and efficiency of all the models can be categorized into three groups, i.e., T1-T6-T7, T2-T4, and T3-T5. It can be observed that the stators in the same group used the same lamination materials and the small deviation is caused by the rotor materials used. This indicates that stators have a much more significant effect on efficiency than rotors.

(c) From Eq. (6), it can be seen that the torque of IPM motors can be improved by increasing the PM flux linkage $\left(\Phi_{m}\right)$ or current (note: materials do not affect the inductance much). However, increasing the current might lead to low efficiency. Therefore, enhancing air gap flux would be the most influential way but the stator and rotor require a redesign.

2.6 Brief Summary It can be observed from the above analysis that, using different materials in the stator and rotor can achieve an equivalent performance to those cases with the stator and rotor having the same materials. Model T1 may have the highest torque but the lowest efficiency and material cost. Model T3 has the lowest torque based on the same
Table 4. Comparison of motor characteristics $\left(110 \mathrm{~A}, 43^{\circ} \mathrm{E}\right)$

\begin{tabular}{cccccc}
\hline Model & Torque (Nm) & Ld $(\mathbf{m H})$ & Lq $(\mathbf{m H})$ & Iron loss(W) & Eff (\%) \\
\hline T1 & 56 & 0.438 & 1.322 & 462 & 92.8 \\
\hline T2 & 55.4 & 0.436 & 1.307 & 252.6 & 94 \\
\hline T3 & 54.6 & 0.435 & 1.286 & 113.5 & 94.8 \\
\hline T4 & 54.9 & 0.438 & 1.289 & 234 & 94.1 \\
\hline T5 & 55.1 & 0.442 & 1.3 & 396.2 & 93.1 \\
\hline T6 & 55 & 0.432 & 1.303 & 138.1 & 94.7 \\
\hline T7 & 55.4 & 0.432 & 1.317 & 174.3 & 94.5 \\
\hline
\end{tabular}

current but the highest efficiency and material cost. With a modest material cost and excellent performance, T7 is considered as a tradeoff design and should be a decent choice. Therefore, T7 [50CS1300(R) + 20CS1500HF (S)] is chosen for further investigation as will be discussed in the following sections.

For the iron losses at the peak torque (@110 A, 43ํㅡ) operation, Table 4 summarizes the simulation results for the seven models investigated. As expected, T1 and T6 have the greatest iron losses. Generally, the iron losses at this condition are smaller than those at high speed.

\section{Performance Analysis with Selected Materials}

Recalling the motor designs shown in Fig. 1 and Table 2, the material combination $\mathrm{T} 7$ will be applied to these five motors. In addition to torque and efficiency, the five IPM motors are also evaluated based on two important performance indices: the flux-weakening ability and saliency ratio, as expressed by (11):

$$
\begin{aligned}
& \max \left(k_{C P S R}\right)=\max \left(\frac{\sqrt{\Phi_{m}^{2}+\left(L_{q} I_{\mathrm{lim}}\right)^{2}}}{\Phi_{m}-L_{d} I_{\lim }}\right) \ldots \ldots \ldots \ldots \ldots \ldots \ldots \ldots \ldots \ldots \ldots \ldots \ldots \ldots \ldots \ldots \ldots \ldots \ldots \ldots \\
& \xi=\frac{L_{q}}{L_{d}} \ldots \ldots \ldots \ldots \ldots \ldots
\end{aligned}
$$

where $k_{C P S R}$, defined to be the ratio of maximum speed to base speed, indicates the capability to achieve constant power speed range (CPSR) due to the weakened field by d-axis current, $\max \left(k_{C P S R}\right)$ is maximum $k_{C P S R}, I_{\text {lim }}$ is current limit $\xi$ and is saliency ratio, indicating the reluctance torque capability. The smaller the term $\left(\Phi_{m}-L_{d} I_{\text {lim }}\right)$ is, the larger the fluxweakening capability can be (12). To accurately evaluate the CPSR, accurate calculation of inductance variation is necessary, which is not a straightforward task, especially when saturation occurs. In this paper, the inductance is computed by the FEM package JMAG and the CPSR can be determined.

3.1 Result Analysis-Saturation Effect The original design is Motor 1, as previously mentioned. Motors 2 and 3 are modified designs based on Motor 1 by changing the distance from the PM center to rotor surface [as the "X1" indicated in Fig. 1(a)] and the stator tooth width [as the "X2" indicated in Fig. 1(a)]. Motor 4 changes the rotor structure of Motor 1, as can be seen in Fig. 1(b) while Motor 5 modifies the number of slots for Motor 4, as indicated in Table 2. The rotor design of Motors 4 and 5 remains the same, as shown in Fig. 1(b). The performance is evaluated by keeping the same number of turns per coil in the windings and the current density of all the motors. The slot fill factor is modified from $45 \%$ (for Motors 1, 2 and 4) to $42.5 \%$ for Motor 3 because of the larger slot area with narrower teeth. The slot fill factor 


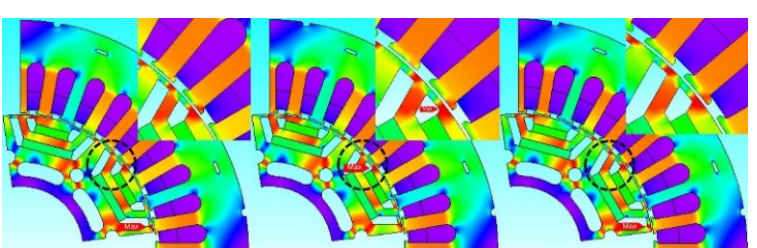

(a) Motor 1

(b) Motor 2

(c) Motor 3

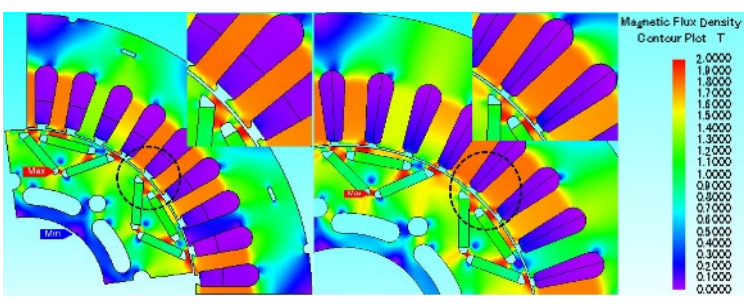

(d) Motor 4

(e) Motor 5

Fig. 9. The magnetic flux density of five motor models

Table 5. Flux density of five IPM motors (@ $110 \mathrm{~A}, 43^{\circ} \mathrm{E}$ )

\begin{tabular}{cccccc}
\hline Items & Motor 1 & Motor 2 & Motor 3 & Motor 4 & Motor 5 \\
\hline B_Stator & $1.56 \mathrm{~T}$ & $1.57 \mathrm{~T}$ & $1.6 \mathrm{~T}$ & $1.6 \mathrm{~T}$ & $1.55 \mathrm{~T}$ \\
\hline B_Rotor & $2.06 \mathrm{~T}$ & $2.04 \mathrm{~T}$ & $2 \mathrm{~T}$ & $2 \mathrm{~T}$ & $1.96 \mathrm{~T}$ \\
\hline B_Air-gap & $0.79 \mathrm{~T}$ & $0.9 \mathrm{~T}$ & $0.79 \mathrm{~T}$ & $1.01 \mathrm{~T}$ & $0.97 \mathrm{~T}$ \\
\hline Torque (Nm) & 55.4 & 56.2 & 52.1 & 59 & 56.8
\end{tabular}

for Motor 5 is $46 \%$ due to its smaller number of slots. Despite the smaller number of slots in Motor 5, the back EMF constant is kept the same as that for Motor 4 and the winding resistance is only $7 \%$ lower. Therefore, they would possess a similar flux weakening capacity under maximum voltage.

The flux density distributions of the five IPM motors at the peak load condition $\left(110 \mathrm{~A}, 43^{\circ} \mathrm{E}\right.$ phase advance) are shown in Fig. 9. It can be seen that the operating regions of the stator teeth of all the motors are around 1.6 T, also as listed in Table 5. This has not saturated the thin lamination (20CS1500HF), even with the rotor providing the highest air gap flux density (Motors 4 and 5) or the stator with the narrowest teeth (Motor 3). The modified designs, Motors 2, 4 and 5 can improve the torque due to their rotor configurations that produce higher air gap flux density (Table 5). The tooth flux density of Motor 3 is higher than Motor 1 but the torque reduces due to the reduction of tooth width with keeping the slot magnetomotive force. The torque and flux density of Motor 5 are slightly smaller than that of Motor 4 due to the modified number of slots. Figure 9 also shows that all the rotor bridges are saturated. Thus, high saturation flux density materials should be used for the rotor to increase the torque and reduce the saturation.

\section{Discussion:}

From Fig. 9 and Table 5, it is known that the thin laminations in the stator may not be saturated with a proper design. Thus, the rotor design becomes the key factor affecting the torque. This also indicates that the use of high flux density materials in the rotor is necessary to improve the torque performance. Therefore, this highlights the advantages of employing material combinations for IPM motors, i.e. low iron loss laminations for stators and high flux density laminations for rotors. Note that the efficiency is almost unaffected.

3.2 Result Analysis-CPSR and Saliency The inductance of each motor is analyzed. Figsures 10-14 show
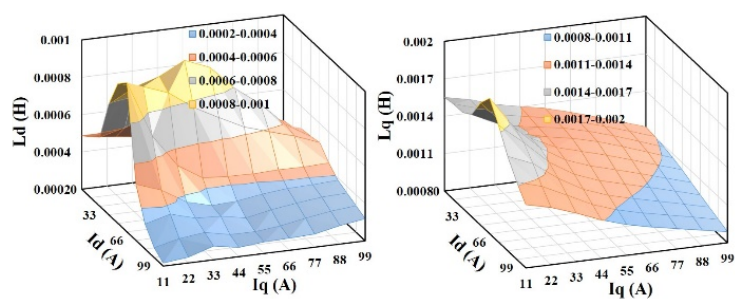

Fig. 10. $d-q$ axis inductances of Motor 1
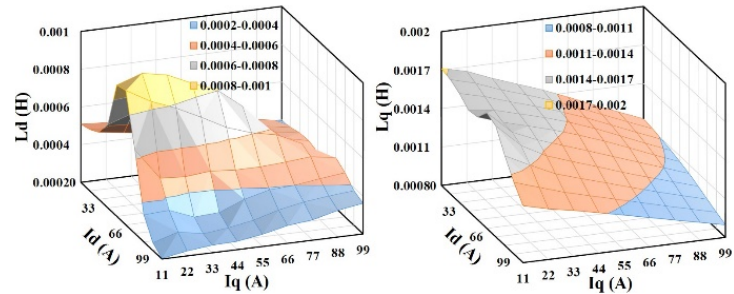

Fig. 11. $d-q$ axis inductances of Motor 2
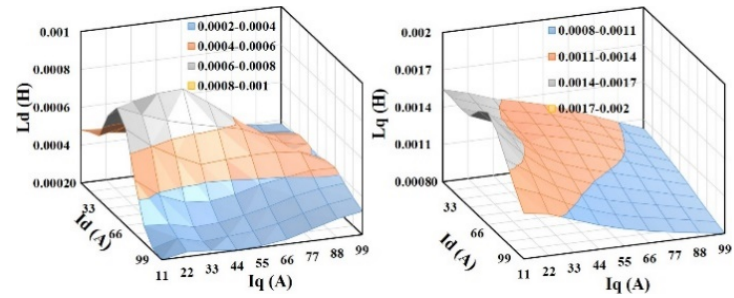

Fig. 12. $\quad d-q$ axis inductances of Motor 3
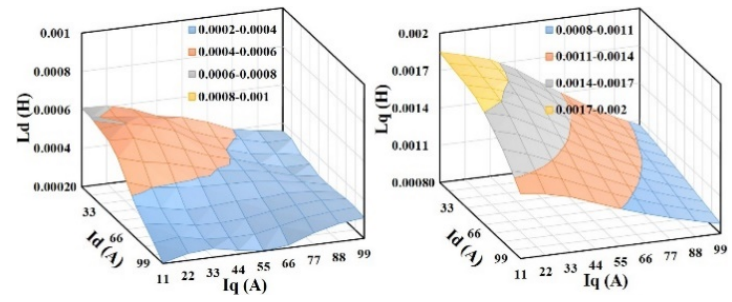

Fig. 13. $d-q$ axis inductances of Motor 4
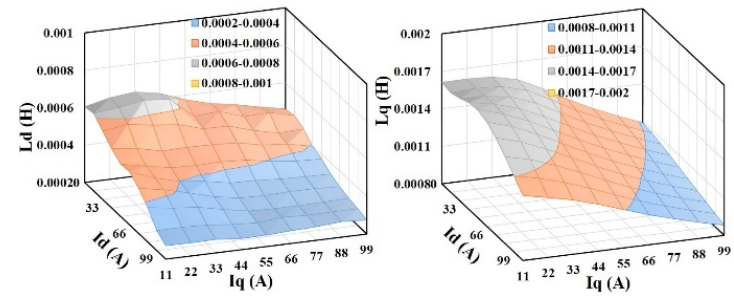

Fig. 14. $\quad d-q$ axis inductances of Motor 5

the inductance profile of the five motors, where the trends of $L_{d}$ and $L_{q}$ of Motors 1, 2, and 3 are different from that of Motors 4 and 5. This is due to the different rotor structures. Based on the inductance profiles, the d-axis inductances of Motors 1 and 2 are higher than that of Motors 3, 4 and 5 . Therefore, it is predicted that the field weakening ability of Motors 1 and 2 are better than that of Motors 3, 4 and 5.

Figures 15 and 16 show the saliency ratios, which range from 2.5 to 5.5 at the condition below the current 77 Arms. The motor performance is not significantly affected by current over 77 Arms. This is due to the $d-q$ axis inductance drops at the saturated condition although the saliency ratio increases. Therefore, it is predicted that $k_{C P S R}$ of the five 


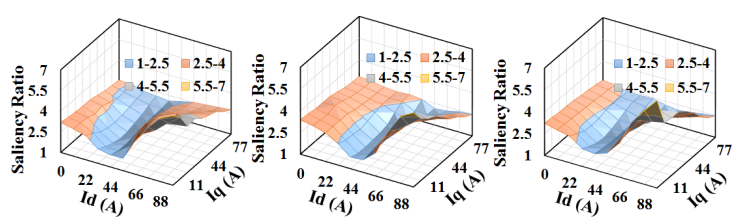

Fig. 15. Saliency ratio of Motor 1, Motor 2, and Motor 3
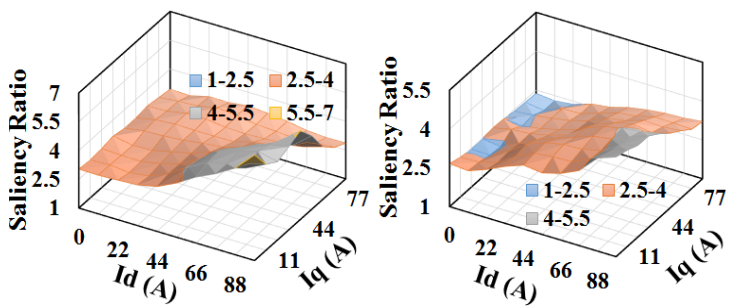

Fig. 16. Saliency ratio of Motor 4 and Motor 5

Table 6. Analysis results of five IPM motors

\begin{tabular}{cccccc}
\hline Items & Motor 1 & Motor 2 & Motor 3 & Motor 4 & Motor 5 \\
\hline$n_{b}(\mathbf{r p m})$ & 1800 & 1800 & 2000 & 1700 & 1700 \\
\hline$\Phi_{m}(\mathbf{W b})$ & 0.0595 & 0.0632 & 0.0596 & 0.0765 & 0.0716 \\
\hline$I_{s}(\mathbf{A r m s})$ & 110 & 110 & 110 & 110 & 110 \\
\hline$L_{d}(\mathbf{m H})$ & 0.421 & 0.442 & 0.419 & 0.527 & 0.506 \\
\hline$L_{q}(\mathbf{m H})$ & 1.29 & 1.13 & 0.934 & 1.45 & 1.22 \\
\hline$\xi$ & 3.06 & 2.56 & 2.23 & 2.75 & 2.41 \\
\hline$k_{\text {CPSR_CAL }}$ & 6 & 5.09 & 4.68 & 5.17 & 5.42 \\
\hline$k_{\text {CPSR_FEA }_{-}}$ & 6.6 & 5.6 & 5 & 5.6 & 6 \\
\hline Efficiency $\eta$ & 94.5 & 94.5 & 94.3 & 93.6 & 93.2 \\
\hline
\end{tabular}

motors ranges from 4 to 6 . Table 6 presents the analysis results for the motors operating at peak condition. The CPSRs calculated by Eq. (7) are compared with that of FEM and the two cases agree well for all the models. It can also be seen that Motor 1 achieves the highest CPSR. Since all the motors have satisfied the basic requirement of $10 \mathrm{~kW}$ output power, Motor 1 based on Model T1 is chosen for prototyping as it has the highest CPSR.

Figure 17 shows the characteristic of electromagnetic torque $T_{e}$ and the output power $P_{\text {out }}$ versus speed at the peak condition. As can be seen, the calculated CPSR using Eq. (7) fits well into the simulations. Therefore, the accurate calculation of inductances is extremely important to evaluate the IPM motor performance. Note that the applied current is the same as that in Figs. 7 and 8.

Based on the previous analysis, a design process to improve the motor performance is presented, as shown in Fig. 18. The rotor should be considered first in this process as its significant effect on torque output. Low iron loss laminations should be used for the stator.

\section{Experimental Validation}

As mentioned above, the prototype of IPM motor was fabricated based on Motor 1, as shown in Fig. 19. The comparisons between the simulation and tests for the torque-power versus speed is shown in Fig. 20. As can be seen, the simulation and experiment agree well. However, the current angle cannot be freely adjusted because a commercial driver was used. In the tests, the current angle was fixed at $43^{\circ} \mathrm{E}$ and the simulations were then re-conducted using this current angle

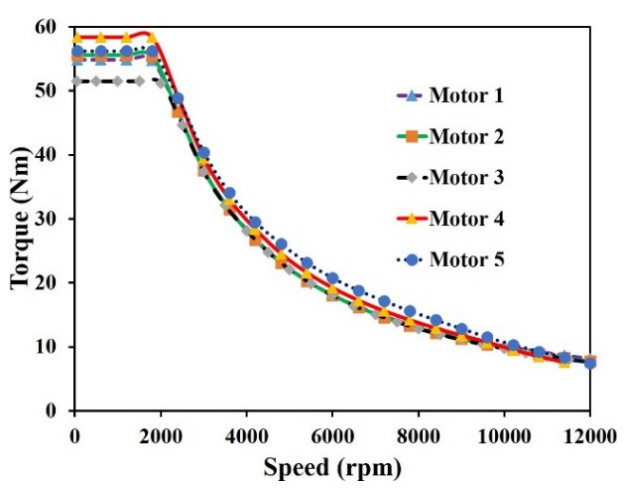

(a) T-N Curve of three motors.

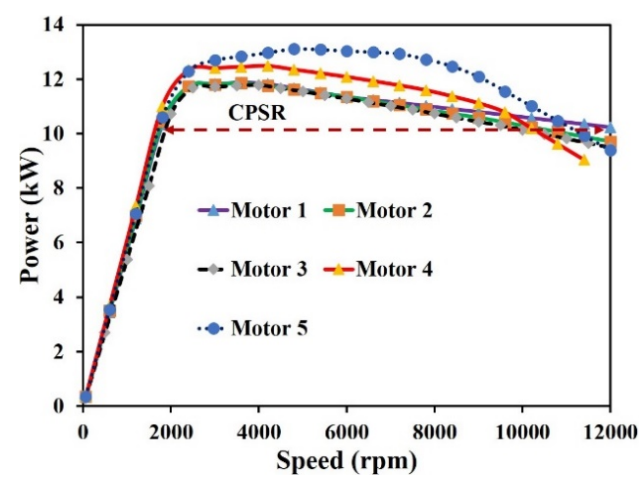

(b) P-N Curve of three motors.

Fig. 17. T-N Curve and P-N Curve of five IPM motors. The straight CPSR line is calculated by Eq. (8)

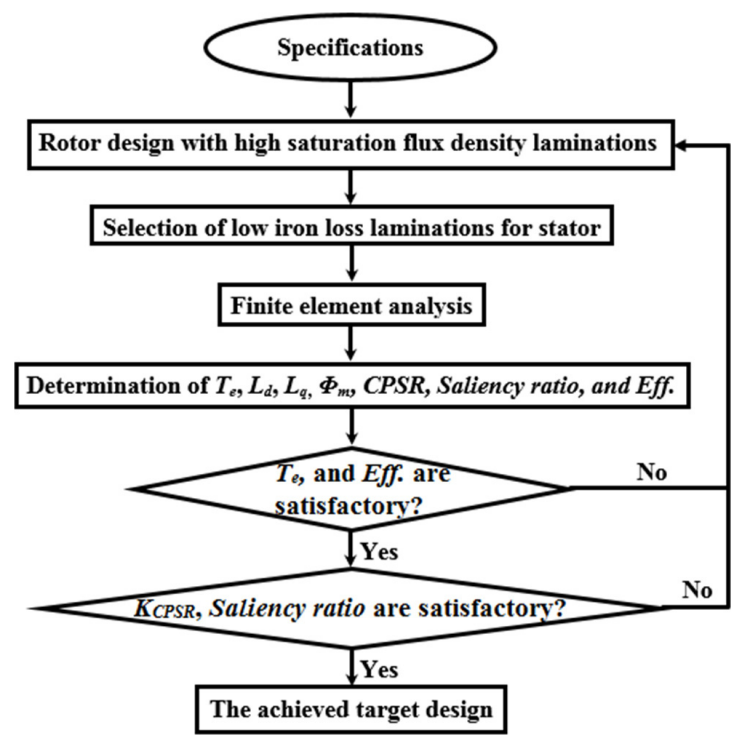

Fig. 18. Design method to improve IPM motor performance

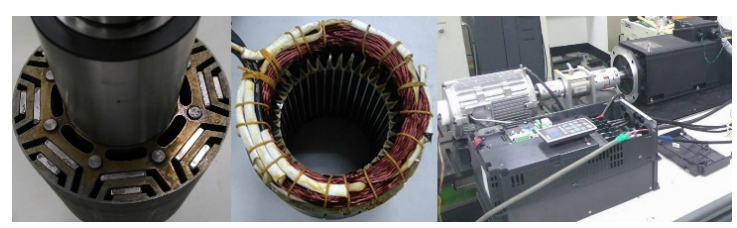

Fig. 19. Prototype of rotor and experimental setup

for direct comparison. This indicates that the motor could not be controlled to reach the maximum speed as stated in the specifications. In addition, the test could not be conducted 


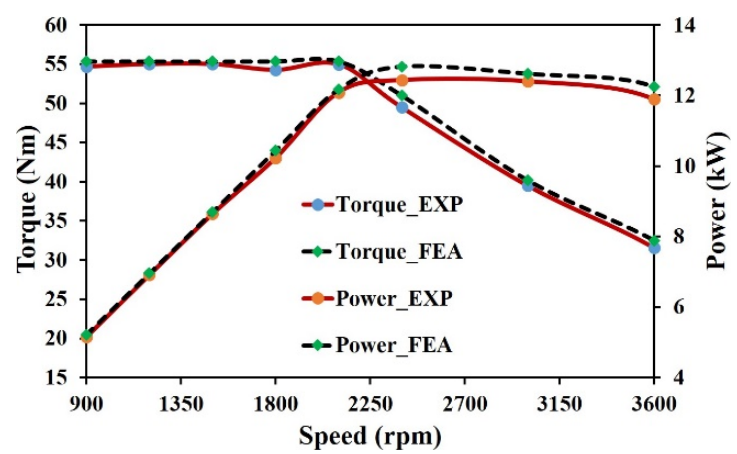

Fig. 20. Comparison of torque and power versus speed (current angle fixed at $43^{\circ} \mathrm{E}$ )

beyond $3600 \mathrm{rpm}$ because of the limitation of the laboratory facilities. Nevertheless, the test results could still validate the reliability of FEM and indirectly validate the design and analysis in this paper.

\section{Conclusions}

This paper has investigated the effect of thin electrical steel laminations on the performance of IPM motors. It was found that the utilization of the high saturation flux density materials in rotor combining with the thin laminations in stator could improve the performance and reduce the cost. The performance of the IPM motors with different rotor structures has been evaluated and compared in terms of torque, efficiency, field weakening ability, and saliency ratio. A design process to improve the motor performance was then proposed based on the analysis. A prototype was fabricated and the experiment has verified the simulations.

\section{Acknowledgment}

This work was supported in part by NSPO of NAR Labs, Taiwan and the project co-funded by China Steel Corporation and Ministry of Science and Technology, Taiwan under contract 104-2622-8-006-001. The author would like to thank Electric Motor Technology Research Center of National Cheng Kung University for technically supporting this work. Mr. Thai Hao Nguyen and Hsiu-Fu Kuo are acknowledged for their assistance in experiments.

\section{References}

( 1 ) R. Cao, C. Mi, and M. Cheng: "Quantitative Comparison of Flux-Switching Permanent-Magnet Motors With Interior Permanent Magnet Motor for EV, HEV, and PHEV Applications", IEEE Trans. Mag., Vol.48, No.8 (2012)

( 2 ) C.-S. Lee, J.-H. Kim, and J.-P. Hong: "Core Loss Effects on Electrical Steel Sheet of Wound Rotor Synchronous Motor for Integrated Starter Generator", J. Mag., Vol.20, No.2, pp.148-154 (2015)

( 3 ) S. Jacobs, D. Hectors, F. Henrotte, M. Hafner, M.H. Gracia, K. Hameyer, and P. Goes: "Magnetic material optimization for hybrid vehicle PMSM drives", World Elec. Veh. J., Vol.3 - ISSN, pp.2032-6653 (2009)
( 4 ) J.-J. Lee, S.-O. Kwon, J.-P. Hong, and K.-H. Ha: "Cogging Torque Analysis of the PMSM for High Performance Electrical Motor Considering Magnetic Anisotropy of Electrical Steel", World Elec. Veh. J., Vol.3 - ISSN, pp.20326653 (2009)

( 5 ) Y. Yanawati, I. Daut, N. Gomesh, S. Nor Shafiqin, M. Abdullah, and I. Pungut: "Comparison Using Different Thickness of None Oriented Electrical Steel Material Using FEM Software", Proc. IEEE Stud. Conf. Res. Dev. SCOReD, pp.356-359 (2010)

( 6 ) H. Hayashi, A. Chiba, and T. Fukao: "Efficiency Comparison of Switched Reluctance Motors with Low Loss Materials", Power Eng. Soc. Gen. Meet., IEEE, pp.1-6 (2007)

( 7 ) N. Yogal, C. Lehrmann, B. Shen, and M. Henke: "Loss comparison of nonoriented electrical steel materials to be used in PMSM under explosion protection aspects", Power Electro. Appl. EPE'15 ECCE-Europe, pp.1-7 (2015)

( 8 ) I. Tanaka, H. Nitomi, K. Imanishi, K. Okamura, and H. Yashiki: "Application of High-Strength Nonoriented Electrical Steel to Interior Permanent Magnet Synchronous Motor", IEEE Trans. Mag., Vol.49, No.6 (2013)

( 9 ) J. Ma, R. Qu, and J. Li: "Optimal Design of an Axial Flux Switched Reluctance Motor with Grain Oriented Electrical Steel”, Elec. Mach. Sys. ICEMS, pp.2071-2077 (2015)

(10) M.N. Ibrahim, P. Sergeant, and E.M. Rashad: "Synchronous Reluctance Motor Performance Based on Different Electrical Steel Grades", IEEE Trans. Mag., Vol.51, No.11 (2015)

(11) G. Pellegrino, A. Vagati, and P. Guglielmi: "Design Tradeoffs Between Constant Power Speed Range, Uncontrolled Generator Operation, and Rated Current of IPM Motor Drives", IEEE Trans. Ind. Appl., Vol.47, No.5 (2011)

(12) X. Liu, H. Chen, J. Zhao, and A. Belahcen: "Research on the Performances and Parameters of Interior PMSM Used for Electric Vehicles", IEEE Trans. Ind. Electron., Vol.63, No.6 (2016)

Thanh Anh Huynh (Non-member) was born in Binh Dinh province,

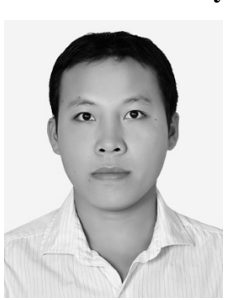
Vietnam. He received the B.Eng. degree in Automation Technology of Department of Mechanical Engineering from HCMC University of Technology and Education, Ho Chi Minh City, Vietnam, in 2010 and M.S. degree in Department of Systems and Naval Mechatronic Engineering from National Cheng Kung University (NCKU), Tainan, Taiwan, in 2014. Now he is a Ph.D. student at National Cheng Kung University. His research interests include electric machine design, drives and applications.

Min-Fu Hsieh (Non-member) received the B.Eng. degree in mechan-

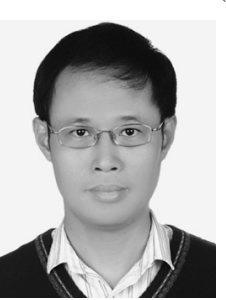
ical engineering from National Cheng Kung University (NCKU), Tainan, Taiwan, in 1991 and the M.Sc. and $\mathrm{Ph} . \mathrm{D}$. degrees in mechanical engineering from the University of Liverpool, U.K. in 1996 and 2000, respectively. From 2000 to 2003, he served as a researcher in the Electric Motor Technology Research Center at NCKU. In 2003, he joined the Department of Systems and Naval Mechatronic Engineering, NCKU, as an Assistant Professor. His areas of interest include electric machine design, drives and mechatronics. In 2012, he was promoted to Full Professor. Prof. Hsieh is a senior member of the IEEE Industry Applications, IEEE Magnetics, and IEEE Industrial Electronics Societies. He is also an Editor to IEEE Transactions on Magnetics and Associate Editor to IEEE Transactions on Industry Applications. 